\title{
Labor Income Risk and Car Insurance in the UK
}

WINFRIED KOENIGER

P.O. Box 7240, 53072 Bonn, Germany koeniger@iza.org (http://www.iza.org)

\begin{abstract}
Microeconomic theory shows that only under certain conditions higher background risk increases the propensity to insure against independent marketable risks. We provide empirical evidence for the case of labor income risk and car insurance in the UK. The main result is that households with higher labor income risk spend more on insurance. This finding is consistent with microeconomic theory if the utility function is of the HARA type. Moreover, we find that households spend more on insurance if they participate in the stock market.
\end{abstract}

Key words: background risk, insurance, United Kingdom

JEL Classification No.: D81, E21, G22

\section{Introduction}

Interactions between labor and financial markets are of particular interest for continental European countries which on the one hand attempt to introduce more flexibility into their labor markets, but on the other hand very often still have quite thin financial markets. Once interactions between labor and financial markets are considered important, the potential of financial markets should no longer be ignored to mitigate the welfare decreasing effects which arise in a world of imperfect markets and risk averse agents as labor markets become more flexible. In this paper we focus on one specific example to shed some light on the importance of these interactions. We are interested in how risk borne in the labor market affects households' attitude towards unrelated risks such as the risk associated with household durables like cars. Microeconomic theory only provides limited guidance to answer this question. The answer depends on conditions that have to be imposed on the utility function or the type of risk (see below). Hence, whether, e.g., households buy more or less insurance for their car if they face higher labor income risk is ultimately an empirical question which we try to answer in this paper.

The main empirical result is that workers exposed to higher labor income risk spend more on car insurance for a given value of the car. Moreover, the empirical evidence suggests that the result is driven by a stronger demand for insurance. This is consistent with microeconomic theory if the utility function is of the HARA type.

We use the Family Expenditure Survey (FES) and National Travel Survey (NTS) for the UK. Merging these data sets gives us information on labor market characteristics and insurance expenditure and allows us to control for households' exposure in the insurable risk. Because of the sample period 1969-95, we are able to exploit variation resulting from 
changes in the labor and financial market in the UK after 1979. We focus on the effect of income risk on car insurance because the available data allows us to control for the exposure in the insurable risk, i.e., the value of the car. Moreover, cars are one of the biggest durable assets in households' balance sheets together with housing. Thus, the decision how much insurance to buy for the car is an important one. Finally, we have enough variation in the data because households nearly always buy more than the mandatory amount of insurance (see Section 4 for further details).

To further motivate our analysis we now want to provide some suggestive evidence which indicates that interactions between the labor and financial market indeed might be relevant in the aggregate. We use employment protection legislation (EPL) as a measure of job security since it is well known that stricter EPL decreases flows in and out of unemployment (see, e.g., Blanchard and Portugal [2001]). Figure 1 shows that non-life insurance penetration, defined as direct gross premiums over GDP, is positively related to the amount of risk borne by individuals in the labor market. In figure 1 we produce a scatterplot of the rank of insurance penetration, where 1 is assigned to the country with the highest insurance penetration, and EPL, where 1 is assigned to the country with the least restrictive EPL and thus the highest risk in the labor market. The rank correlation is positive and significant at the 5\% level. The results are unchanged for the $90 \mathrm{~s}$ or if we use insurance per capita as an alternative measure. The empirical evidence based on micro data presented below is consistent with this suggestive aggregate evidence.

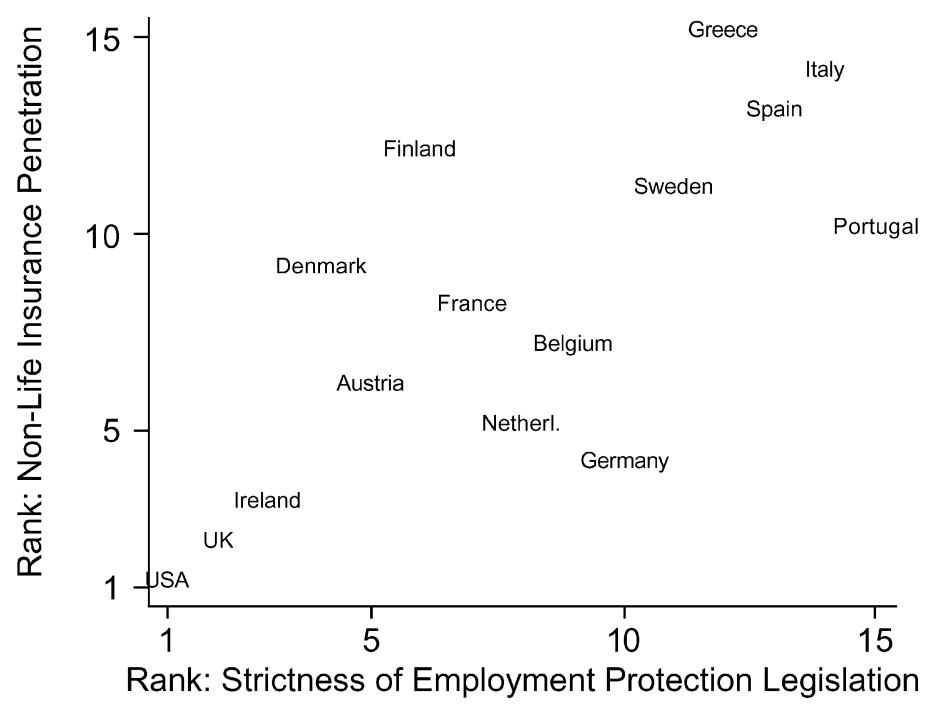

Figure 1. Rank correlation between insurance penetration and employment protection legislation for the $80 \mathrm{~s}$ (highest insurance penetration, rank $=1$; most flexible EPL, rank $=1$ ). Sources: The data for insurance penetration are from OECD [1991, 1998]. The sample of countries is determined by data availability. Some data are omitted because they are not comparable according to the OECD notes. The data for the indicator on employment protection legislation are reported in OECD ([1999], Table 2.5.) The indicator summarizes information on the strictness of employment protection legislation for regular and temporary employment as well as collective dismissals. 


\subsection{Existing literature}

Empirical research has focussed on the effect of labor income risk on portfolio choice. Gakidis [1998] and Vissing-Jorgensen [2002] use the PSID, assume an income process and use the variance of income realizations as proxy for income risk. Souleles [2001] uses the Consumer Expenditure Survey and looks at the effect of standard deviations of consumption growth on portfolio choice. Guiso, Jappelli and Terlizzese [1996] use the Bank of Italy Survey of Household Income and Wealth (SHIW) and Souleles [2001] uses the Michigan Consumer Sentiment Survey to exploit direct information on perceived income risk. Haliassos and Bertaut [1995] use educational and occupational proxies for income risk contained in the Survey of Consumer Finances for the US. All these papers find some support for the hypothesis that higher labor income risk decreases the demand for risky assets.

Only Guiso and Jappelli [1998] investigate the effect of labor income risk on insurance demand. Using the SHIW, they find that households with higher income risk are more likely to buy health or casualty insurance. Moreover, conditional on buying insurance households with higher income risk spend more on insurance. However, the SHIW does not allow Guiso and Jappelli to control for the households' exposure. Controlling for the size of the insurable exposure is crucial because households can reduce risk by holding less of the asset at risk or by insuring the risky asset relatively more (see Eeckhoudt, Meyer and Ormiston [1997] for a formal exposition). By considering the specific case of motor-vehicle insurance, we are able to construct a proxy for the insurable exposure of households: the value of the car. This allows us to isolate the effect of labor income risk on insurance from its effect on the size of the insurable asset. Furthermore, we use repeated cross-sectional data that allow us to address estimation problems arising with pure cross-sectional data as in Guiso and Jappelli [1998]. Finally, in our sample period (1969-95) labor and financial markets were reformed in the UK after Ms. Thatcher took power in 1979. This gives us additional variation which helps to disentangle supply and demand effects and to address self selection.

The structure of the rest of the paper is as follows. In Section 2 we present the theoretical background needed for our specific empirical application. We discuss the empirical specification in Section 3. We describe the structure of the British car insurance market in Section 4 and the data in Section 5. In Section 6 the results are presented and discussed before we conclude in Section 7.

\section{Theoretical background}

Insurance markets are a special case of markets for contingent claims. Arrow [1964] and Debreu [1959, ch. 7] developed contingent claim analysis to establish the well-known result that in perfect and complete markets consumption of optimally insured individuals should only depend on aggregate wealth. These kind of insurance contracts are not observed in reality for reasons of transaction costs, moral hazard and/or adverse selection. E.g., Chiu and Karni [1998] analyze the provision of unemployment insurance in a setting where adverse selection and moral hazard interact and can explain why private unemployment insurance does not exist. ${ }^{1}$ Hence, households cannot fully eliminate their idiosyncratic component 
of labor income risk. Moreover, fluctuations of labor income influence the amount of risk households are willing to bear in other markets.

An introduction of labor income risk - the background risk in our application-does not generally increase the demand for insurance. However, this is unambiguously the case once regularity conditions are imposed on the utility function, such as proper risk aversion (Pratt and Zeckhaeuser [1987]), standard risk aversion (Kimball [1993]), or risk vulnerability (Gollier and Pratt [1996]). Assuming decreasing absolute risk aversion and decreasing absolute prudence is sufficient and implies standard risk aversion, the strongest of the three concepts mentioned above. Another sufficient condition is that absolute risk aversion be decreasing and convex. Interestingly, all HARA utility functions feature convex absolute risk aversion and thus imply higher insurance demand after an introduction of background risk (see Gollier and Pratt [1996] and Gollier [2001]). Eeckhoudt, Gollier and Schlesinger [1996] derive the regularity conditions for a deterioration of the distribution of background risk in the sense of first-order and second-order stochastic dominance to result in an increase of risk aversion. These theoretical results imply that ultimately it is an empirical question whether higher income risk induces households to spend more on insurance.

In general the effect of labor income risk on insurance demand depends on the households' utility maximizing joint decision on wealth accumulation, insurance demand and portfolio choice (see, e.g., Mayers and Smith [1983]). We are not able to analyze this joint decision with the available data. However, we are able to answer the more moderate question whether households with a higher labor income risk spend more on insurance conditional on wealth and the value of the car.

\section{Empirical specification}

Already simple models with non-durable consumption and insurance do not have a closedform solution for insurance demand. Moreover, structural estimation would require strong non-testable assumptions such as a just-identifying assumption on the distribution of losses which we do not observe in our data. Hence, we choose to perform a reduced-form estimation where we try to gain insights on the effects of supply and demand by sample splits and using variation across time.

Because we have a repeated cross-sectional data set, we cannot track households' income over time. Moreover, the FES does not contain any directly reported measure of income risk for households. Thus, we cannot avoid an assumption to disentangle idiosyncratic risk and variation resulting from heterogeneity. We identify subpopulations which differ with respect to their labor income risk and investigate which subpopulations demand more car insurance on average.

This approach is different from the one of Banks, Blundell and Brugiavini [2001] who assume a specific income process and thus are able to decompose risk into aggregate, cohort, and idiosyncratic components using repeated cross-sectional data. However, as in our analysis, it is only possible under certain assumptions to disentangle idiosyncratic risk and variance resulting from cross-sectional heterogeneity. In Banks et al. deviations from the age-cohort mean measure idiosyncratic risk. Age cohorts, however, are quite 
heterogenous and heterogeneity is only partly observable. We choose occupational risk proxies. Occupational groups are likely to be more homogenous so that more of the withingroup income variance is attributable to idiosyncratic risk than to heterogeneity.

Furthermore, idiosyncratic risk is not eliminated for subpopulations. Were it only for moral hazard, idiosyncratic risk should not exist for any subpopulation because it is possible to observe subpopulation averages. These will be taken as given by individuals if the subpopulation's size is big enough. Thus, it is in principle possible to write insurance contracts which are based on the observable averages such that all idiosyncratic risk is eliminated. However, it is not possible to fully insure the subpopulation's income stream under limited commitment, i.e., if insurance contracts can be broken at any point in time (see, e.g., Hayashi [1996]). It turns out that empirically idiosyncratic risk plays a role for subpopulations so that choosing subpopulation membership as proxy for labor income risk is a feasible strategy. For the UK, e.g., Banks and Johnson [2001] provide evidence of income variations of subpopulations.

We choose the subpopulations of unskilled manual and skilled non-manual workers where the reference group are unskilled non-manual and skilled manual workers. This leaves us with a sufficient cell size per year and age-cohort. We choose occupational groups because unobservables, like ability, which are potentially influencing income risk are supposedly similar in the respective occupational ${ }^{2}$ categories. This choice is supported, e.g., by Schmitt [1995], Table 5.5, for the UK in the 80s. Moreover, occupational variables are often used as instruments which shall be correlated with consumption variability (e.g., Dynan [1993]).

Our sample consists of households in the working age (see Section 5 for more details). Since we exclude self-employed from our sample because of problems of underreporting, labor income risk is mainly employment risk. Thus, we provide some empirical support for our hypothesis by looking at male full-time employment for the respective subpopulations. ${ }^{3}$ In Table 1 we display sample means of the proportion of the respective subpopulation which is full-time employed. We observe that there is less full-time employment in the lower segment of the labor market; and that the difference is larger in the 80s and 90s than in the 70 s.

Since theoretical papers use concepts of stochastic dominance to derive comparative static results, we report the results comparing the cumulative distribution functions for the occupational groups. ${ }^{4}$ Figure 2 illustrates in the upper two panels that the income distribution of the unskilled workers is dominated by the one of skilled non-manual workers in the sense of first-order stochastic dominance. The dominance becomes slightly more pronounced in

Table 1. Full-time employment of skilled and unskilled workers 1969-95.

\begin{tabular}{lccccc}
\hline & \multicolumn{2}{c}{$1969-79$} & & \multicolumn{2}{c}{$1980-1995$} \\
\cline { 2 - 3 } Male full-time employment & Mean & Std. dev. & & Mean & Std. dev. \\
\hline Unskilled manual & .92 & .27 & & .73 & .44 \\
Skilled non-manual & .98 & .13 & & .96 & .2 \\
\hline
\end{tabular}

Source: FES, author's calculation. 

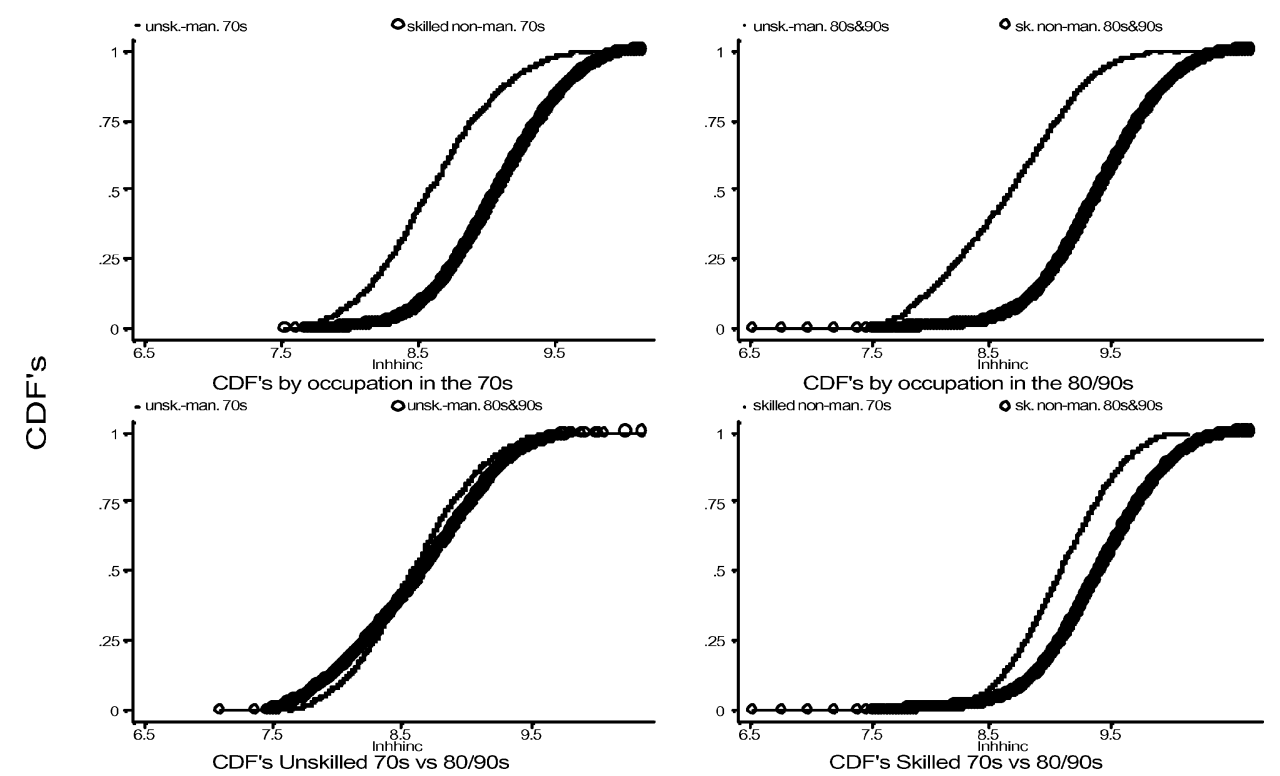

Figure 2. Cumulative distribution functions of log-(annual)-household income by occupation and decade (includes transfer income). Source: FES, author's calculation.

the 80 s and 90 s because the income distribution of the skilled non-manual shifts favorably in the 80s and 90s (see the lower right panel) whereas the distribution of the unskilled manual nearly remains unchanged (the lower left panel).

Because unskilled workers are over-represented in the pool of long-term unemployed in the UK (OECD [1993]), cross-sectional evidence might pick up variation resulting from heterogeneity rather than income risk. However, empirical evidence of Nickell, Jones and Quintini [2002] supports our choice of occupations as income risk proxies. Using the UK Labor Force Survey and the New Earnings Survey for the 80s and 90s they find that unskilled manual workers have the highest percentage probability to become unemployed whereas skilled non-manual workers have the smallest probability (see Nickell, Jones and Quintini [2002], Table 1). They do not find evidence that this difference has become more pronounced within the $80 \mathrm{~s}$ and $90 \mathrm{~s}$. Moreover, they find that unskilled workers are more likely to face real hourly wage cuts of more than $10 \%$ than skilled workers. The difference between the two groups becomes smaller in the 80s and 90s, however. Finally, the cost of unemployment in terms of wage losses has increased across skill groups, but less so for unskilled workers.

The bottom line of our own empirical evidence extracted from the FES and the evidence from Nickell, Jones and Quintini [2002] is that in the UK unskilled manual workers face more labor income risk than the reference group of skilled manual and unskilled non-manual workers whereas skilled non-manual workers face less labor income risk than the reference group. There is some evidence that the differences between occupational groups become less pronounced in the 80 s and 90 s. 
Using occupations as measures for income risk, the equation we estimate in the case in which we control for selection is of the following type:

$$
\begin{aligned}
\text { mvins }_{i t}= & a_{0}+a_{1} X_{i t}+a_{2} \text { valcar }_{i t}+b_{1} \text { sknman }_{i t}+b_{2}\left[\text { sknman }_{i t} * \text { valcar }_{i t}\right] \\
& +b_{3}\left[\text { sknman }_{i t} * X_{i t}\right]+c_{1} \text { unskman }_{i t}+c_{2}\left[\text { unskman }_{i t} * \text { valcar }_{i t}\right] \\
& +c_{3}\left[\text { unskman }_{i t} * X_{i t}\right]+\lambda m_{i t}+\eta_{t}+\theta_{c}+\varepsilon_{i t},
\end{aligned}
$$

where mvins $_{i t}$ is the expenditure on motor vehicle insurance of household $i$ in period $t$, $X$ contains a set of controls including a proxy for liquid wealth, valcar is the value of the car, sknman is a dummy for skilled non-manual workers, unskman is a dummy for unskilled manual workers, $\eta_{t}$ is a year dummy, $\theta_{c}$ is the cohort dummy of age-cohort $c,{ }^{5}$ and $m_{i t}$ is the inverse Mill's ratio controlling for selection. The coefficients we are interested in are $b_{2}$ and $c_{2}$. We try to detect whether unskilled manual workers are insuring themselves relatively more per unit of car value given that they are exposed to more labor income risk, i.e., $c_{2}>0$. Accordingly, we expect the skilled non-manual workers to insure themselves less, i.e., $b_{2}<0$. The other regressors are inserted to control for observable heterogeneity. In particular, the dummies sknman and unskman are supposed to pick up heterogeneity of the two subpopulations which we are not able to control for otherwise. The time dummies control for aggregate changes such as changes in the competitiveness of the insurance industry. Because some households do not have a car and hence do not demand any insurance, we perform Tobit estimations. We then investigate whether selection plays a role estimating a Heckman selection model. Before we present the results we briefly give an overview over the British insurance market and the data sets.

\section{The insurance market in the UK}

The insurance sector in the UK was well developed already before 1979 as noted by Finsinger, Hammond and Tapp [1985, p. 105]. This is confirmed by suggestive evidence from OECD-data for the years 1983-96 on the penetration ratio for non-life insurance which is defined as direct gross premiums over GDP. This is an indicator for the importance of the domestic insurance industry. The penetration ratio is $4.1 \%$ in 1984 compared to $4.6 \%$ in 1996. Its smallest value is $3.6 \%$ in 1983 and the maximum is 5.3\% in 1993. Hence, there is no clear sign that the insurance industry has become much more important in the sample period. Moreover, the data reveals that the insurance industry in the UK has always been the most developed in Europe in the period 1983-96.

We focus on motor-vehicle insurance because the data allows us to control for households' exposure. This is crucial for the analysis because households facing higher labor income risk might simply lower their exposure by decreasing their worth exposed to risk instead of buying more insurance. In the context of motor-vehicle insurance that means buying a cheaper car. Since cars account for around $85 \%$ of the vehicle stock in our sample period (Department of Environment, Transport and the Regions [1997]), controlling for the value of the stock of cars allows us to account for changes in the exposure. Additionally, the motor-vehicle insurance market has a considerable depth because every household owning 
a car is obliged to buy a minimum amount of insurance. More than $50 \%$, at the end of the sample about $70 \%$, of the households demand a positive amount of motor-vehicle insurance. The minimum insurance is far from complete because there exists a variety of additional coverage possibilities which leaves us with enough variation. The Road Traffic Act requires all motorists to be insured against liabilities for third parties only. Information of the Association of British Insurers [1998] on motor-vehicle insurance reveals that two thirds of the motorists demand comprehensive coverage, most of the rest insures against third-party liabilities, fire and theft and a very small proportion of the population demands only the obligatory insurance coverage. Finally, information from the Association of British Insurers and the big British insurance company Royal \& SunAlliance confirm that the skillcontent of an occupation does not affect insurance premiums. The exception is a premium discount for public employees, which are mostly skilled, by some insurance companies (see Finsinger, Hammond and Tapp [1985]). We will address this issue in the estimations below.

\section{The data}

Because idiosyncratic risk by definition washes out in the aggregate the use of micro data is essential for the questions we are interested in. We use the Family Expenditure Survey (FES) and National Travel Survey (NTS) for the UK. Merging these data sets gives us information on labor market characteristics, insurance expenditure and the value of the car. Moreover, we are able to control for households' exposure in the insurable risk. Finally, the sample period 1969-95 provides useful variation resulting from changes in labor and financial market institutions in the UK after 1979 when Ms. Thatcher took power.

The Family Expenditure Survey (FES) for the UK is a repeated cross-sectional survey of around 7,000 households per year where 10,000 households are contacted initially. The data are collected by face-to-face interview or diaries. The survey contains information on motor-vehicle insurance, income, consumption, geographic and demographic variables.

Since we are dealing with a survey, we have to consider underreporting of certain measures which is not necessarily random across the population, and other sources of measurement error. However, Atkinson and Micklewright [1983] report that underreporting is only substantial for investment income, the income of self-employed and alcohol consumption. The reliability of the FES is confirmed for later years by the papers in Banks and Johnson [1998]. Underreportings and biases are reasonably constant so that changes over time are interpretable. Additionally, we will use the National Travel Survey (NTS) to impute the value of the car. For the construction of the variables value of the car, urban and the issue of company cars see the Appendix.

Our sample is constructed as follows. We exclude households from the sample where either the household head or his partner are self-employed. As mentioned above self-employed tend to substantially underreport income. Moreover, if the vehicle stock used by the selfemployed is used for their business, then their labor income risk and the risk associated with the vehicle stock are positively correlated. We have no information on the type and size of the business risk in the data. Hence, if we found that the self-employed demanded more insurance, we could not identify whether this would be resulting from higher labor income risk or a stronger positive correlation between the two sources of risk. In this paper 
we are interested in the former. We exclude households where the household head is retired or older than 53 since the consequences of income risk become negligible close to the retirement age which is 65 (60) years for males (females). This leaves us with 7 five-year age cohorts for the population between the age of 18 and 53 in a single cross section. We exclude households reporting zero food consumption. Finally, we exclude households from Northern Ireland because it is too different from the rest of the UK in many respects.

The monetary variables are converted to real terms using the retail price index and the price index for motor-vehicle tax and insurance ${ }^{6}$ which is constructed by the Office for National Statistics using the FES. We aggregate individual monetary variables to the household level because otherwise we have the measurement problem that individual income, consumption or wealth can in principle be arbitrarily shifted across household members in our survey. Hence, idiosyncratic risk which is eliminated within the household is neglected in our analysis. Assuming perfect within-household insurance would eliminate the problem we would like to analyze. As Dynarski and Gruber [1997] point out, however, within-household insurance is non-negligible in the US, but fails to eliminate all idiosyncratic risk.

We report the summary statistics of the variables used in Table 2 at the end of the paper. Monetary variables are defined in 1996 British pounds. The mean of the stock of cars is of the same order of magnitude as reported in Davies, Devereux and Weber [1992]. Comparing the unconditional means with the means conditional on spending a positive amount of insurance we observe that the sample means of the demographic variables differ (Insurance and the value of the car are larger by definition since it is obligatory to insure the car). Hence, unobservable characteristics might differ as well so that we have to account for sample selection if we want to retrieve estimates for the whole population. We now briefly discuss the controls before we report the results.

\subsection{Choice of controls}

Some of the controls are supposed to control for supply-side effects, others for demand-side effects. We will use controls for the whole population and the subpopulation because we do not want our results for the subpopulation to be driven by demographic differences.

(a) Adults: The number of adults using the car will determine the insurance premium. We expect the coefficient to be positive.

(b) Children: Together with adults the number of children is supposed to control for the household size. On the one hand households with children might be relatively more liquidity constrained from a life-cycle point of view. Then we would expect the coefficient to be positive. On the other hand family cars are cheaper to insure which would result in a negative sign.

(c) Married: Married households might have a stronger commitment to share income sources and thus provide more intra-household insurance. Moreover, married households are more likely to buy family cars which are in general cheaper to insure. We expect the sign to be negative.

(d) Sex: Women often get charged less for insurance; we thus expect a negative sign. 
Table 2. Summary statistics.

\begin{tabular}{|c|c|c|c|}
\hline & Nobs & Mean & Std. err. \\
\hline \multicolumn{4}{|c|}{ Unconditional means } \\
\hline Expenditure on motor-vehicle insurance & 84705 & 183.18 & 220.30 \\
\hline Value of the car & 84705 & 1590.45 & 1343.30 \\
\hline Wealth-interest income & 84705 & 377.78 & 3208.89 \\
\hline Children & 84705 & 1.26 & 1.23 \\
\hline Married (= 1 if married) & 84705 & 0.73 & 0.45 \\
\hline $\operatorname{Sex}(=1$ if female $)$ & 84705 & 0.15 & 0.36 \\
\hline Adults & 84705 & 1.97 & 0.67 \\
\hline Urban* & 84705 & 0.23 & 0.42 \\
\hline Unskilled manual & 84705 & 0.04 & 0.20 \\
\hline Skilled non-manual & 84705 & 0.24 & 0.43 \\
\hline \multicolumn{4}{|c|}{ Means conditional on a positive insurance expenditure } \\
\hline Expenditure on motor-vehicle insurance & 57052 & 271.97 & 218.88 \\
\hline Value of the car & 57052 & 2319.22 & 966.21 \\
\hline Wealth-interest income & 57052 & 455.21 & 3746.47 \\
\hline Children & 57052 & 1.22 & 1.18 \\
\hline Married (= 1 if married) & 57052 & 0.81 & 0.40 \\
\hline $\operatorname{Sex}(=1$ if female $)$ & 57052 & 0.09 & 0.28 \\
\hline Adults & 57052 & 2.08 & 0.64 \\
\hline Urban* & 57052 & 0.22 & 0.41 \\
\hline Unskilled manual & 57052 & 0.03 & 0.17 \\
\hline Skilled non-manual & 57052 & 0.28 & 0.45 \\
\hline
\end{tabular}

Notes: Data from FES and NTS 1969-95. The sample consists of the population between age 20 and 53 .

It excludes self-employed, households from Northern Ireland and households reporting zero food consumption.

*Dummy variable which takes the value 1 if households live in Greater London or in the region North West.

(e) Wealth interest income: This variable shall proxy the household's wealth. The FES only contains wealth interest income and this not in a sufficiently disaggregated form to be able to construct the stock of wealth. If absolute risk aversion is decreasing, we expect a negative sign, given that we control for the value of the car.

(f) Value of the car: We expect the sign to be positive because more exposure increases insurance demand ceteris paribus.

(g) Urban: Living in an urban neighborhood increases the insurance premium; we expect a positive sign.

One shortcoming is that postal codes seem to be a determinant of insurance premiums in the UK, presumably because they proxy the safety of the neighborhood, the amount of traffic etc. Firstly, we have postal codes for some years only and secondly we do 
not have information how to match them to premiums. However, the quality of the neighborhood is probably correlated with wealth, a variable we control for.

(h) Cohort dummies: We use cohort dummies to control for cohort fixed effects in our data. This is standard in the estimation of repeated cross-sectional data and explained more in Blundell et al. [1998]. We choose five-year age cohorts to estimate the cohort fixed effect with enough precision.

\section{Results}

We focus on insurance expenditure and not on portfolio choice because the FES contains only information on investment income and not on stocks of risky assets. However, estimates for the relationship between labor income risk - as proxied by our occupational categoriesand participation in the stock market which are not reported confirm results in Haliassos and Bertaut [1995] for the US and are in line with results of Attanasio, Banks, and Tanner [2002] on stock market participation in the UK. Households exposed to more labor income risk are less likely to participate in the stock market. This is consistent with the evidence we present now on the relationship between labor income risk and insurance expenditure.

We first present the results without controlling for possible selection of the sample. The coefficients are representative for the part of the population owning a car. We omit the year and cohort dummies in the output, but report joint F-statistics for their significance. The main result of the Tobit estimation reported in Table 3, displayed in bold font, is that those parts of the population more exposed to labor income risk have a significantly higher propensity to insure. Unskilled manual workers spend 8 pence more on insurance per pound of car owned whereas skilled non-manual workers spend 4 pence less per pound of car owned than the rest of the sample.

Let's now turn to the other coefficients. Motor-vehicle insurance depends positively on the value of the car. For a car worth 2319 pounds, which is the sample average conditional on buying a positive amount of insurance (see Table 2), households pay 441 pounds of insurance. Unskilled manual workers spend significantly less on motor-vehicle insurance whereas skilled non-manual workers spend significantly more on motor-vehicle insurance than the rest of the population. The subpopulation dummies shall capture unobservable differences in car characteristics (e.g., sports cars) and in individual characteristics influencing the premium (e.g., driving records). Note that most other variables have the expected sign. The exception is the sign of wealth interest income which is positively significant. Interestingly, Guiso and Jappelli [1998] also find a positive effect of households' resources on insurance expenditure. They rationalize this coefficient by pointing out that households' resources might be positively correlated with their insurable exposure. Since we control for the households' direct exposure in terms of the asset at risk, taken at face value the positive sign implies that absolute risk aversion is not decreasing and thus utility functions are not of the HARA type. However, one should be careful with such a conclusion for the following reasons: firstly, wealth interest income is only an imperfect measure of the stock of wealth and secondly, risk exposure might interact dynamically with wealth accumulation. Higher labor income risk might induce households to accumulate more assets so that those more exposed to risk end up with a higher stock of wealth and spend more on insurance. 
Table 3. Tobit estimation for car insurance expenditure 1969-1995.

\begin{tabular}{|c|c|c|c|c|c|c|}
\hline \multirow[t]{2}{*}{$\begin{array}{l}\text { Nobs: } \\
\text { Loglik. }\end{array}$} & \multicolumn{6}{|c|}{$\begin{array}{l}-399,473 \\
\text { Dependent variable: Expenditure on motor vehicle insurance }\end{array}$} \\
\hline & \multicolumn{5}{|c|}{$\begin{array}{l}\text { Dependent variable: Expenditure on motor vehicle insurance } \\
\text { Coef. } \quad \text { Std. err. } \quad z \quad P>z\end{array}$} & \\
\hline Value of the car & 0.19 & 0.00 & 169.55 & 0.00 & & \\
\hline Wealth-interest income & 0.01 & 0.00 & 16.03 & 0.00 & & \\
\hline Children & 12.60 & 0.90 & 14.01 & 0.00 & & \\
\hline Married $(=1$ if married $)$ & -121.08 & 3.74 & -32.35 & 0.00 & & \\
\hline $\operatorname{Sex}(=1$ if female $)$ & -49.64 & 4.08 & -12.18 & 0.00 & & \\
\hline Adults & 86.79 & 1.78 & 48.74 & 0.00 & & \\
\hline Urban* & 18.32 & 2.42 & 7.56 & 0.00 & & \\
\hline Unskilled manual & -73.69 & 18.23 & -4.04 & 0.00 & & \\
\hline Skilled non-manual & 42.26 & 8.27 & 5.11 & 0.00 & & \\
\hline \multirow[t]{2}{*}{ Constant } & -413.68 & 8.01 & -51.62 & 0.00 & & \\
\hline & \multicolumn{5}{|c|}{ nteraction of unskilled-manual with } & \\
\hline Value of the car & 0.08 & 0.01 & 13.43 & 0.00 & & \\
\hline Wealth-interest income & 0.00 & 0.01 & -0.53 & 0.60 & & \\
\hline Children & 17.48 & 3.75 & 4.66 & 0.00 & & \\
\hline Married (= 1 if married) & 10.09 & 16.07 & 0.63 & 0.53 & & \\
\hline $\operatorname{Sex}(=1$ if female $)$ & -0.71 & 19.21 & -0.04 & 0.97 & & \\
\hline Adults & 1.07 & 7.13 & 0.15 & 0.88 & & \\
\hline \multirow[t]{2}{*}{ Urban* } & 12.68 & 11.02 & 1.15 & 0.25 & & \\
\hline & \multicolumn{5}{|c|}{ Interaction of skilled non-manual with } & \\
\hline Value of the car & -0.04 & 0.00 & -21.18 & 0.00 & & \\
\hline Wealth-interest income & 0.00 & 0.00 & -2.55 & 0.01 & & \\
\hline Children & -6.22 & 1.85 & -3.35 & 0.00 & & \\
\hline Married (= 1 if married) & -45.56 & 7.06 & -6.45 & 0.00 & & \\
\hline $\operatorname{Sex}(=1$ if female $)$ & 14.72 & 8.79 & 1.67 & 0.09 & & \\
\hline Adults & -1.23 & 3.63 & -0.34 & 0.74 & & \\
\hline \multirow[t]{2}{*}{ Urban* } & 14.42 & 4.56 & 3.16 & 0.00 & & \\
\hline & & & & & & P-value \\
\hline Joint F-test for year-dummies: & & & $F(26,8$ & 46) & 162.68 & 0 \\
\hline Joint F-test for cohort-dummies: & & & $F(10,8$ & 46) & 187.72 & 0 \\
\hline
\end{tabular}

Notes: Data from FES and NTS 1969-95. The sample consists of the population between age 20 and 53.

It excludes self-employed, households from Northern Ireland and households reporting zero food consumption.

*Dummy variable which takes the value 1 if households live in Greater London or in the region North West.

We summarize the main result in figure 3 . Using our parameter estimates, we plot insurance demand as a function of the car-value in the relevant region. The function with the larger slope is the one of the unskilled manual and the function with the smaller slope is the one of the skilled non-manual workers. For the rest of the population we normalize the 


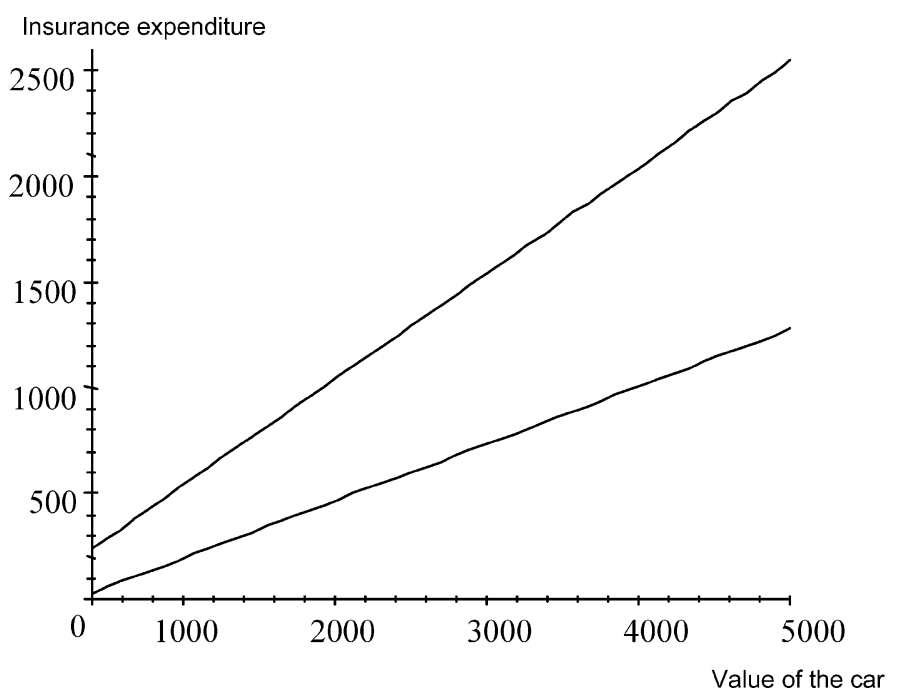

Figure 3. Insurance expenditure as a function of the car value: skilled non-manual (smaller slope) and unskilled manual (larger slope). Source: FES, authors calculation; note that we start plotting the curves at the minimum car value of those owning a car.

expenditure for insurance to zero at a car value of zero. For those households owning a car the average car value is 1672 (486) pounds for the unskilled manual and 3116 (738) pounds for the skilled non-manual workers (standard deviations are reported in brackets). Hence, unskilled manual workers are exposed to more labor income risk and not surprisingly also have less valuable cars on average.

\subsection{Robustness and extensions}

We now will use sample splits in order to gain confidence that the results are not driven by unobservable heterogeneity or supply-side effects but are due to differences in labor income risk. $^{7}$

6.1.1. Endogenous choice of occupations and premium discounts. We investigate whether our results are robust when we drop employees of the public sector from our sample. We have to restrict the sample period to 1969-86 because information on industry sectors is not available afterwards. On the one hand this exercise will tell us whether endogenous occupational choice influences our results (see, e.g., Guiso and Paiella [2001]). More risk averse households might prefer employment in the public sector. This might offset the effect of smaller employment risk on insurance demand and downward bias our coefficients because only a negligible portion of public employees performs unskilled manual work. On the other hand Finsinger, Hammond and Tapp [1985] report that some insurance companies give premium discounts for employees in the public sector. The results reported in Table 5 show that none of the two effects matter for our sample. 
Table 4. Tobit estimation for car insurance expenditure with decade interactions.

\begin{tabular}{|c|c|c|c|c|c|c|c|c|}
\hline \multirow[t]{2}{*}{$\begin{array}{l}\text { Nobs: } \\
\text { Loglik. }\end{array}$} & $\begin{array}{l}\text { 84,705 Cer } \\
-399,144 \\
\text { Dependent }\end{array}$ & $\begin{array}{l}\text { ns. obs.: } 2 \\
\text { t variable }\end{array}$ & $\begin{array}{l}\text { 7,653 Unc } \\
\text { Expendit }\end{array}$ & $\begin{array}{l}\text { obs.: } 5 \\
\text { ure on } \mathrm{m}\end{array}$ & $\begin{array}{l}57,052 \\
\text { notor vehi }\end{array}$ & icle insura & & \\
\hline & Coef. & Std. err. & $z$ & $P>z$ & Coef. & Std. err. & $z$ & $P>z$ \\
\hline \multicolumn{9}{|c|}{ Interaction with a dummy for the 80 s and $90 \mathrm{~s}$} \\
\hline Value of the car & 0.20 & 0.00 & 102.03 & 0.00 & -0.01 & 0.00 & -4.98 & 0.00 \\
\hline Wealth-interest income & 0.01 & 0.00 & 9.15 & 0.00 & 0.00 & 0.00 & -1.64 & 0.10 \\
\hline Children & 16.65 & 1.36 & 12.27 & 0.00 & -5.81 & 1.82 & -3.19 & 0.00 \\
\hline Married (= 1 if married) & -106.79 & 7.55 & -14.14 & 0.00 & -22.07 & 8.71 & -2.53 & 0.01 \\
\hline $\operatorname{Sex}(=1$ if female $)$ & -33.33 & 8.49 & -3.92 & 0.00 & -18.14 & 9.67 & -1.87 & 0.06 \\
\hline Adults & 45.79 & 3.03 & 15.11 & 0.00 & 61.95 & 3.71 & 16.70 & 0.00 \\
\hline Urban* & 18.02 & 3.85 & 4.68 & 0.00 & 1.03 & 4.94 & 0.21 & 0.84 \\
\hline Unskilled manual & -101.10 & 30.10 & -3.36 & 0.00 & 33.73 & 38.04 & 0.89 & 0.38 \\
\hline Skilled non-manual & 38.54 & 16.28 & 2.37 & 0.02 & 8.93 & 18.95 & 0.47 & 0.64 \\
\hline Constant & -343.19 & 10.88 & -31.54 & 0.00 & & & & \\
\hline \multicolumn{9}{|l|}{ Interaction of unskilled-manual with } \\
\hline Value of the car & 0.09 & 0.01 & 10.16 & 0.00 & $-\mathbf{0 . 0 3}$ & 0.01 & -2.78 & 0.01 \\
\hline Wealth-interest income & 0.01 & 0.02 & 0.39 & 0.70 & -0.02 & 0.02 & -0.77 & 0.44 \\
\hline Children & 21.56 & 4.92 & 4.38 & 0.00 & -11.42 & 7.67 & -1.49 & 0.14 \\
\hline Married (= 1 if married) & 4.07 & 27.36 & 0.15 & 0.88 & 9.26 & 34.24 & 0.27 & 0.79 \\
\hline $\operatorname{Sex}(=1$ if female $)$ & -27.71 & 36.26 & -0.76 & 0.45 & 38.15 & 42.80 & 0.89 & 0.37 \\
\hline Adults & 10.06 & 10.64 & 0.95 & 0.34 & -2.42 & 14.37 & -0.17 & 0.87 \\
\hline Urban $*$ & 7.26 & 15.42 & 0.47 & 0.64 & 12.05 & 22.03 & 0.55 & 0.58 \\
\hline \multicolumn{9}{|c|}{ Interaction of skilled non-manual with } \\
\hline Value of the car & $-\mathbf{0 . 0 3}$ & 0.00 & -7.91 & 0.00 & -0.01 & 0.00 & $-\mathbf{3 . 5 3}$ & 0.00 \\
\hline Wealth-interest income & -0.01 & 0.00 & -5.15 & 0.00 & 0.01 & 0.00 & 4.38 & 0.00 \\
\hline Children & -4.35 & 2.93 & -1.48 & 0.14 & -2.10 & 3.78 & -0.56 & 0.58 \\
\hline Married (= 1 if married) & -32.01 & 14.83 & -2.16 & 0.03 & -8.42 & 16.95 & -0.50 & 0.62 \\
\hline $\operatorname{Sex}(=1$ if female $)$ & -38.91 & 18.83 & -2.07 & 0.04 & 75.69 & 21.28 & 3.56 & 0.00 \\
\hline Adults & -25.54 & 6.55 & -3.90 & 0.00 & 33.06 & 7.87 & 4.20 & 0.00 \\
\hline \multirow[t]{2}{*}{ Urban* } & 21.04 & 7.68 & 2.74 & 0.01 & -9.44 & 9.53 & -0.99 & 0.32 \\
\hline & & \multicolumn{7}{|c|}{$P$-value } \\
\hline Joint F-test for year-dummies: & \multicolumn{2}{|c|}{$F(26,84623)$} & & 149.11 & 0 & & & \\
\hline Joint F-test for cohort-dummies: & $F(10,8462$ & & & 183.57 & 0 & & & \\
\hline
\end{tabular}

Notes: Data from FES and NTS 1969-95. The sample consists of the population between age 20 and 53. It excludes self-employed, households from Northern Ireland and households reporting zero food consumption. * Dummy variable which takes the value 1 if households live in Greater London or in the region North West. 
Table 5. Comparison of the results w/ and w/o the employed of the public sector 1969-1986.

\begin{tabular}{|c|c|c|c|c|c|c|c|c|}
\hline & \multicolumn{4}{|c|}{ Sample w/o publicly employed } & \multicolumn{4}{|c|}{ Full sample } \\
\hline & Coef. & Std. err. & $z$ & $P$-value & Coef. & Std. err. & $\mathrm{z}$ & $P$-value \\
\hline $\begin{array}{l}\text { Interaction of unskilled manual } \\
\text { and value of the car }\end{array}$ & 0.08 & 0.01 & 13.77 & 0.00 & 0.08 & 0.01 & 14.48 & 0.00 \\
\hline $\begin{array}{l}\text { Interaction of skilled non-manual } \\
\text { and value of the car }\end{array}$ & -0.03 & 0.00 & -14.80 & 0.00 & -0.03 & 0.00 & -16.64 & 0.00 \\
\hline
\end{tabular}

6.1.2. The 70s versus the 80s and 90s. As mentioned above Nickell, Jones and Quintini [2002] report that differences in labor income risk between skilled and unskilled occupations become less pronounced in the 80s and 90s. Indeed we find in Table 4 that the difference of insurance expenditure per car value between unskilled manual and skilled non-manual workers decreases from .12 in the 70 s (the difference of the coefficients in bold font in the left column) to .1 (considering the changes of the coefficients displayed in bold font in the right column) in the $80 \mathrm{~s}$ and $90 \mathrm{~s}$. This suggests on the one hand that our proxies for labor income risk are indeed valid and on the other hand that the demand effects resulting from changes in labor income risk matter.

6.1.3. Endogenous skill accumulation. One might wonder whether endogenous skill accumulation induces the changes of the coefficients in the $80 \mathrm{~s}$ and $90 \mathrm{~s}$. To get a first insight whether this is indeed the case we drop all households in the sample whose household head was younger than 25 years old in 1979. The idea is that basic educational choices of this population have been done before changes in the labor market institutions could be anticipated since it is more difficult to upgrade skills while being in the labor market. To generate the same age structure in both subsamples we adjust the first half of the sample in the same way. The results displayed in Table 6 reveal that the results for the coefficients of interest remain nearly constant quantitatively.

6.1.4. Insurance and stock market participation. We add a dummy for stock market participation $^{8}$, shares, to our baseline specification in order to get an impression whether and how interactions between portfolio composition and insurance matter. The sign of the coefficients is an empirical matter because theory gives little guidance about the sign

Table 6. Endogenous skill accumulation: Sample of those older than 25 in 1979.

\begin{tabular}{|c|c|c|c|c|}
\hline & Coef. & Std. err. & $z$ & $P$-value \\
\hline Interaction of unskilled manual and value of the car & 0.08 & 0.01 & 9.03 & 0.00 \\
\hline Interaction of skilled non-manual and value of the car & -0.03 & 0.00 & -7.43 & 0.00 \\
\hline \multicolumn{5}{|l|}{ Interaction with dummy for 80 s and $90 \mathrm{~s}$} \\
\hline Interaction of unskilled manual and value of the car & -0.02 & 0.01 & -1.59 & 0.11 \\
\hline Interaction of skilled non-manual and value of the car & -0.01 & 0.00 & -1.14 & 0.26 \\
\hline
\end{tabular}


Table 7. Results including stock market participation as a regressor.

\begin{tabular}{lcccc}
\hline & Coef. & Std. err. & $z$ & P-value \\
\hline Shares (dummy = 1 if shares owned) & 35.91 & 3.66 & 9.80 & 0.00 \\
Interaction with & & & & \\
$\quad$ Unskilled manual & -49.13 & 24.50 & -2.01 & 0.05 \\
$\quad$ Skilled non-manual & -5.56 & 5.44 & -1.02 & 0.31 \\
\hline
\end{tabular}

one should expect (a sufficient condition for two risks to be substitutes is given in Gollier [2001]). We report only the estimates for the coefficients of the new regressors in Table 7 because the coefficients of the other regressors remain qualitatively the same. Interestingly, stock market participation increases insurance expenditure, i.e., the coefficient of shares is significantly positive. This suggests that risk borne in the stock market does not hedge some of the households' other risks. ${ }^{9}$ The coefficient of the interaction of the dummy for the unskilled manual workers and stock market participation is negative but imprecise because only very few unskilled actually do participate in the stock market. Moreover, the coefficient of the interaction of the skilled and stock market participation is not significant.

6.1.5. Self-selection. Selection issues might arise because of changes in the population of car owners, i.e., those who demand a positive amount of insurance. It turns out that car ownership for the unskilled manual workers increases significantly in the sample period: from 32 to $53 \%$ with the biggest increase of 13 percentage points in 1982 when downpayment requirements for car purchases fell significantly (see Marshall [1996]). The percentage of skilled non-manual owning a car changes much less from 70 to $80 \%$ but company cars play a role for skilled non-manual workers whereas they are not important for unskilled manual workers: the percentage of skilled non-manual workers having company cars increases from 20 to $40 \%$ in the sample period. However, more than half of the households with company cars own an additional car in the 80s and 90s whereas this is the case for only $20 \%$ at the beginning of the sample, so that company cars are less likely to imply that households own no car at all in the second part of the sample.

We use a specific subset of cohort-year interactions as instruments to control for selection. As mentioned above, in 1982 downpayment requirements for car purchases decreased substantially. This might have induced especially young liquidity constrained households to buy cars in the years afterwards. Hence, we use cohorts which are in the sample before and after 1982. The instruments are then interactions of their cohort dummies with year dummies for the years 1982 to 1985 if the household head is younger than 35 . Three of the cohort-year interactions turn out to be jointly positively significant at the $1 \%$ level and are used as instruments. The estimation results presented in Table 8 show that the results of the Tobit estimations survive. The effect becomes quantitatively smaller, however. Unskilled manual workers spend 2 pence more on insurance in the 70 s than the reference population whereas there is some evidence that this is no longer the case in the $80 \mathrm{~s}$ and $90 \mathrm{~s}$ (the coefficient for the change in the 80 s and 90 s is only significant on the $11 \%$ level). The effect for skilled non-manual workers is no longer significant. The correlation between the residual 
Table 8. Heckman selection.

\begin{tabular}{|c|c|c|c|c|}
\hline & Coef. & Std. err. & $z$ & $P$-value \\
\hline Interaction of unskilled manual and value of the car & 0.02 & 0.01 & 1.83 & 0.07 \\
\hline Interaction of skilled non-manual and value of the car & 0.0005 & 0.0049 & 0.11 & 0.91 \\
\hline \multicolumn{5}{|l|}{ Interaction with dummy for 80 s and 90 s } \\
\hline Interaction of unskilled manual and value of the car & -0.02 & 0.02 & -1.61 & 0.11 \\
\hline Interaction of skilled non-manual and value of the car & -0.0034 & 0.0056 & -0.61 & 0.54 \\
\hline \multirow[t]{2}{*}{ Correlation between residuals } & -0.11 & 0.01 & -7.41 & 0.00 \\
\hline & & & $P$-value & \\
\hline Joint test for significance of the instruments & $\operatorname{chi} 2(3)$ & 10.53 & 0.01 & \\
\hline
\end{tabular}

of the selection equation and the equation estimating insurance expenditure is negative and significant. This has an intuitive rationalization. Unobservables like liquidity constraints make households less likely to buy a car, but let them buy relatively more insurance if they own a car since liquidity constraints make the value function more concave.

\section{Conclusion}

We provide empirical evidence that households exposed to higher labor income risk spend more on insurance against independent, insurable risks. Sample splits suggest that this results at least partly from more demand for insurance. The results are consistent with microeconomic theory if the utility function is of the HARA type. The evidence obtained with micro data confirms the aggregate evidence presented in the Introduction that interactions between financial and labor markets are important. Thus countries attempting to render labor markets more flexible, should also make financial markets more competitive in order to allow households to efficiently manage their exposure. Indeed, relatively developed financial markets might have facilitated the political process of labor market reform in the UK in the 80 s and 90 s.

As we pointed out above we do not take account of dynamic general equilibrium effects in our estimations, but only answer the more moderate question whether households with a higher labor income risk demand more insurance conditional on wealth and the value of the car. We investigate the dynamic interactions more in future research.

\section{Appendix}

\section{Construction of value of the car}

The methodology of the imputation is similar to the one described in Davies, Devereux and Weber [1992]. However, we impute the value of car(s) for households whereas they impute values for cohorts. The adjusted $R^{2}$ statistic for the regression of the value of the car on household characteristics is 0.24 which shows that we capture a reasonable amount of 
variation. Note that we impute different car values for the different occupations so that we explicitly control for different values of the vehicle stock for the occupational risk indicators. This allows us to control for adjustments of the insurable assets. We use information on households that only have company cars and exclude these from the imputation for the value of owned cars. We need to impute values for company cars for the sample period before 1982. We check the quality of the imputation by calculating the correlation of the imputed and actual variable in the period 1982-95. The correlation is 0.74 and significant. Further details are available on request.

\section{Construction of urban}

Unfortunately, there is no variable available for the whole sample which indicates whether households live in an urban or rural neighborhood. The FES only contains information about households living in "Greater London or other conurbations" for the years 1969-73 and 1982-95. Fortunately, we have information about the region, in which the household lives, for the whole sample period so that we can construct a proxy for urban neighborhoods. The correlation between urban and the variable indicating households living in metropolitan areas for the period where we observe both is 0.55 and significant.

\section{Acknowledgments}

I thank Giuseppe Bertola for innumerous comments as well as Rob Alessie, Sascha Becker, Michael Burda, Louis Eeckhoudt, Chris Flinn, Christian Gollier, Luigi Guiso, Michael Haliassos, Massimo Motta, Guglielmo Weber, and seminar participants at the EUI, IZA, and the meetings of the ARIA and EGRIE 2001. The Association of British Insurers, Royal $\&$ SunAlliance Insurance and Karen Dennison from the Data Archive provided most useful information. The Family Expenditure Survey (FES) and National Travel Survey (NTS) were used by permission of the ONS and supplied by the Data Archive at the University of Essex. Financial support by the DAAD, European University Institute, and the chair "Finance and Consumption in the EU" is gratefully acknowledged.

\section{Notes}

1. Another stream of literature suggests that households' exposure to idiosyncratic risk is an optimal, i.e., endogenous response in a setting without commitment where consumers are sufficiently impatient, contract partners have symmetric information, and it is impossible for third parties to enforce the contract (see Hayashi [1996], Kocherlakota [1996] and their references).

2. We do not report results for subpopulations which differ with respect to education. This is because the data does contain information on education only since 1978 so that a comparison of labor market regimes is impossible for these subpopulations. However, the categories of unskilled manual and skilled non-manual workers are highly correlated with low and high education, respectively. Moreover, we are not able to control for education in the imputation procedure for the value of the car.

3. It is well known that females tend to work more part-time than males. Hence, in Table 1 we focus on male employment because we do not want the unconditional means to be influenced by changes in the gender distribution in the subpopulation over time. 
4. Results using the coefficient of variation are similar.

5. Recall that we cannot control for individual fixed effects because the data are repeated cross-sectional.

6. Before 1974 we have to use the price index for motoring.

7. We also checked robustness in a number of different dimensions. We used non-durable consumption as a proxy for wealth instead of wealth interest income. The results remain qualitatively unchanged. The results are robust as well with respect to different years used to split the sample and to using only the sample of male household heads.

8. In the FES we have information whether households have wealth income from shares, mutual funds, and debentures for the period 1969-95. In 1978 there were no data entries so that we omitted that year.

9. As long as we consider stock market participation as predetermined no estimation problems arise resulting from endogeneity. If endogeneity matters, we are likely to overestimate the positive effect of stock market participation on insurance. Better insured households might be more likely to participate in the stock market.

\section{References}

ARROW, K. [1964]: "The Role of Securities in the Optimal Allocation of Risk-Bearing," Review of Economic Studies, 31, 91-96.

ASSOCIATION OF BRITISH INSURERS [1998]: Motor Insurance, http://www. abi.org.uk/CONSUMER/ motor/motoins/MotoIns.asp.

ATKINSON, A.B. and MICKLEWRIGHT, J. [1983]: "On the Reliability of Income Data in the Family Expenditure Survey," Journal of the Royal Statistic Society, 146, 33-61.

ATTANASIO, O.P., BANKS, J., and TANNER, S. [2002]: "Asset Holding and Consumption Volatility," Journal of Political Economy, 110, 771-792.

BANKS, J., BLUNDELL, R., and BRUGIAVINI, A. [2001]: "Risk Pooling, Precautionary Saving and Consumption Growth," Review of Economic Studies, 68, 757-779.

BANKS, J. and JOHNSON, P. (eds.) [1998], How Reliable is the Family Expenditure Survey?-Trends in Incomes and Expenditures over Time, IFS, London.

BLANCHARD, O. and PORTUGAL, P. [2001]: "What Hides Behind an Unemployment Rate: Comparing Portuguese and U.S. Labor Markets," American Economic Review, 91, 187-207.

BLUNDELL, R., DUNCAN, A., and MEGHIR, C. [1998]: "Estimating Labor Supply Responses using Tax Reforms," Econometrica, 66, 827-861.

CHIU, W.H. and KARNI, E. [1998]: "Endogenous Adverse Selection and Unemployment Insurance," Journal of Political Economy, 106, 806-827.

DAVIES, J., DEVEREUX, M., and WEBER, G. [1992]: "Vehicle Stocks, Vehicle Purchases and Credit in the Family Expenditure Survey," Institute for Fiscal Studies, mimeo.

DEPARTMENT OF ENVIRONMENT, TRANSPORT AND THE REGIONS [1997]: Transport Statistics, Spring 1997, http://www.detr.gov.uk/transtat/spring97/ spring97.htm.

DEBREU, G. [1959]: Theory of Value. New York: Wiley.

DYNAN, K.E. [1993]: "How Prudent are Consumers?,” Journal of Political Economy, 101, 1104-1113.

DYNARSKI, S. and GRUBER, J. [1997]: "Can Families Smooth Variable Earnings?," Brookings Papers on Economic Activity, 1, 229-299.

EECKHOUDT, L., GOLLIER, C., and SCHLESINGER, H. [1996]: "Changes in Background Risk and Risk Taking Behavior," Econometrica, 64, 683-689.

EECKHOUDT, L., MEYER, J., and ORMISTON, M.B. [1997]: "The Interaction Between the Demands for Insurance and Insurable Assets," Journal of Risk and Uncertainty, 14, 25-39.

FINSINGER, J., HAMMOND, E., and TAPP, J. [1985]: "Insurance: Competition or Regulation? — A Comparative Study of the Insurance Markets in the United Kingdom and the Federal Republic of Germany," IFS Report Series No. 19, London.

GAKIDIS, H.E. [1998]: "Stocks for the Old? Earnings Uncertainty and Life-Cycle Portfolio Choice," MIT, mimeo. GOLLIER, C. [2001]: The Economics of Risk and Time, Cambridge: MIT Press. 
GOLLIER, C. and PRATT, J.W. [1996]: "Risk Vulnerability and the Tempering Effect of Background Risk," Econometrica, 64, 1109-1123.

GUISO, L. and JAPPELLI, T. [1998]: "Background Uncertainty and the Demand for Insurance against Insurable Risks," The Geneva Papers on Risk and Insurance Theory, 23, 7-27.

GUISO, L., JAPPELLI, T., and TERLIZZESE, D. [1996]: "Income Risk, Borrowing Constraints and Portfolio Choice," American Economic Review, 86, 158-172.

GUISO, L. and PAIELLA, M. [2001]: "Risk Aversion, Wealth and Financial Market Imperfections," CEPR Discussion Paper No. 2728.

HALIASSOS, M. and BERTAUT, C.C. [1995]: "Why Do So Few Hold Stocks?,” Economic Journal, 105, 11101129.

HAYASHI, F. [1996]: “Analysis of Household Saving: Past, Present, and Future,” The Japanese Economic Review, 47, 21-33.

KIMBALL, M.S. [1993]: "Standard Risk Aversion," Econometrica, 61, 589-611.

KOCHERLAKOTA, N.R. [1996]: "Implications of Efficient Risk Sharing without Commitment," Review of Economic Studies, 63, 595-609.

MARSHALL, N. [1996]: "Services," in Industrial Policy in Britain, David Coates (Ed.), MacMillan Press Ltd., London, pp. 62-84.

MAYERS, D. and SMITH, C.W.Jr. [1983]: “The Interdependence of Individual Portfolio Decisions and the Demand for Insurance," Journal of Political Economy, 91, 304-311.

NICKELL, S., JONES, P., and QUINTINI, G. [2002]: “A Picture of Job Insecurity Facing British Men,” Economic Journal, 112, 1-27.

OECD [1993]: "Long Term Unemployment: Selected Causes and Remedies," Ch. 3 , Employment Outlook, Paris, pp. 83-117.

OECD [1991, 1998]: Insurance Statistics Yearbook, Paris.

OECD [1999]: "Employment Protection and Labour Market Performance," Ch. 2, Employment Outlook, Paris, pp. 49-132.

PRATT, J.W. and ZECKHAEUSER, R. [1987]: "Proper Risk Aversion,” Econometrica, 55, 143-154.

SCHMITT, J. [1995]: "Male Earnings in Britain," in Differences and Changes in Wage Structures, R.B. Freeman and L.F. Katz (Eds.), NBER, Comparative Labor Market Series, University of Chicago Press, pp. 177-204.

SOULELES, N.S. [2001]: "Household Portfolio Choice, Transaction Cost, and Hedging Motives," University of Pennsylvania, mimeo.

VISSING-JORGENSEN, A. [2002]: "Towards an Explanation of Household Portfolio Choice Heterogeneity: Nonfinancial Income and Participation Cost Structures," University of Chicago, mimeo. 